\title{
Metode Rasulullah SAW Mendidik Ahl Ash-Shuffah
}

\section{Radiman}

Guru Pendidikan Agama Islam SD Negeri Gunungtelu 01, Kec. Karangpucung, Kab.

Cilacap

E-mail: endimclp@hotmail.com

\begin{abstract}
This study aims to find out the method of the Prophet Muhammad educated Ahl al-Shuffah and the relevance of the method of the Prophet Muhammad to educate Ahl al-Shuffah with current Islamic education. The research method used is descriptive qualitative research design that aims to describe and to summarize various conditions, various situations, or various phenomena of social reality which exist in the community as the object of research. Analysis the data obtained in this study uses the Content Analysis strategy as a method of analyzing text and language. The results show that the method of the Prophet Muhammad in educating Ahl al-Shuffah included the method of giving advice, motivation methods / الترغيب, Intimidation / الترهيب methods, exemplary methods, discussion methods, persuasion methods, court methods, blessing methods, memorization, mulazamah, and game method. Then, this method shows the relevance that is closely related to the development of general education and Islamic education, especially at the present time
\end{abstract}

Keywords: Ash-Shuffah, Islamic Education, Method

\section{Pendahuluan}

Pendidikan pada masa sekarang telah menjadi salah satu kebutuhan pokok manusia. Pengembangan yang dilakukan untuk mencapai hasil maksimal dari proses pendidikan terus dilakukan. Kurikulum pendidikan terus berkembang dan cenderung mengalami perkembangan yang akseleratif. Indonesia telah melaksanakan program pendidikan yang sering disebut sebagai wajib belajar. Program wajar 6 tahun, wajar 9 tahun sudah berjalan dan saat ini mulai berlaku rintisan wajar 12 tahun menuju pendidikan dengan prinsip long life education. Pendidikan Islam adalah pendidikan yang senantiasa membimbing manusia untuk maju (Aly, 1999:137). 


\section{Radiman}

Nabi Muhammad SAW telah memberikan pendidikan kepada umat manusia yang ada di kota Makkah sekitarnya selama kurang lebih 13 tahun. Pendidikan pada masa ini menghasilkan para sahabat yang kokoh dalam keimanan dan keislaman. Dan tiba saatnya Allah swt. memberi perintah kepada Nabi Muhammad SAW dan muslimin untuk hijrah ke Yatsrib. Muhajirin yang tidak mendapatkan tempat berlindung maka Rasulullah menempatkan mereka di ash-Shuffah dan Anshar memberikan bantuan akomodasi bagi mereka.

Ash-Shuffah yang awalnya dipergunakan sebagai tempat bernaung dan berlindung dari ekstrimnya cuaca, terus berkembang menjadi tempat pembinaan Muslimin langsung dibawah bimbingan dan pengawasan Nabi Muhammad SAW. Ash-Shuffah telah terbukti menghasilkan sahabat-sahabat yang cerdas secara jasmani, akal maupun rohaninya. Diantaranya adalah Ubadah bin ash-Shamit yang mampu mengajarkan menulis, Abu Hurairah yang terkenal karena banyaknya hafalan hadisnya dan Hudzaifah bin al-Yaman yang menaruh perhatian dengan hadis-hadis fitnah. Namun kesibukan mereka dalam ilmu dan ibadah, bukanlah menjadi sebab mereka memencilkan diri dari masyarakat dalam perkara-perkara kemasyarakatan dan mengangkat senjata dalam jihad. Bahkan di antara mereka banyak yang syahid di medan pertempuran ('Umary, 1983:96).

Penelitian dengan tema Metode Rasulullah SAW mendidik Ahl Ash-Shuffah dibatasi oleh kandungan metode pendidikan dalam hadis-hadis tentang Ahl Ash-Shuffah. Dengan mempertimbangkan waktu dan biaya untuk melakukan penelitian ini maka penulis membatasi pencarian hadis pada kitab al-Jami'ash-Shahih li Abi Abdullah Muhammad ibn Isma'il alBukhariy ( Shahih Bukhari ) dan terjemahnya. Fokus permasalahan pada penelitian ini adalah bagaimana metode Rasulullah SAW mendidik Ahl Ash-Shuffah? Dan bagaimana relevansi metode Rasulullah SAW mendidik Ahl Ash-Shuffah dengan pendidikan Islam saat ini?

\section{Tinjauan Teoritis}

At-Turmusy (tt:6) berpendapat, "sesungguhnya hadis itu bukan hanya yang 


\section{Metode Rasulullah SAW Mendidik ...

dimarfu'kan kepada Nabi SAW saja, melainkan dapat pula disebutkan pada apa yang "mauquf" (dihubungkan dengan perkataan, dan sebagainya dari sahabat), dan apa-apa yang "maqthu"'(dihubungkan dengan perkataan dan sebagainya dari tabi'in)". Sejalan dengan pengertian ini, 'Itr memaknai hadis sebagai "apa-apa yang disandarkan kepada Nabi SAW dari perkataan, atau perbuatan atau taqrir atau sifat-sifat bawaannya atau budi pekertinya atau disandarkan kepada sahabat maupun tabi'in ('Itr, 1979M/ 1399H:27). Rahman (1999) berpandangan bahwa untuk menerima hadis dari Nabi Muhammad SAW maka ada tiga unsur hadis yang tidak boleh ditinggalkan, yaitu rawy, matan dan sanad (hadis). Rawy ialah orang yang menyampaikan atau menuliskan dalam suatu kitab apa-apa yang pernah didengar dan diterima dari seseorang (gurunya. Matan atau matnu'l-hadis dimaknai sebagai pembicaraan (kalam) atau materi berita yang diover oleh sanad yang terakhir. Sanad atau thariq, ialah jalan yang dapat menghungkan matnul-hadis kepada junjungan kita Nabi Muhammad SAW.

Kata ash-Shuffah banyak tersebar dalam kitab-kitab hadis. Winsick dalam al-Mu’jam al-Mufahrash li Alfadzi al-Hadis an-Nabawi ( 1955, juz 3:323-324)

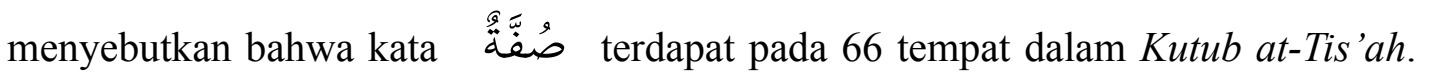
Dalam al-Mu'jam al-Wasith (1425H:517), ash-Shuffah dalam pengertian bahasadengan mendhommahkan shod dan mentasydidkan fa-ialah: naungan, tanah lapang yang luas yang lebih tinggi dari tanah sekitar dan memiliki atap. Sedangkan secara istilah adalah bagian dari masjid yang memiliki naungan yang menjadi tempat perlindungan bagi orang-orang miskin. Atau ia adalah tempat yang yang memiliki naungan di masjid al-Madinah, di mana orang-orang faqir dari kaum al-Muhajirin berlindung di dalamnya dan Rasulullah SAW menjaganya mereka, dan mereka disebut ashab ash-Shuffah.

Ahl Ash-Shuffah - disebutkan pula ashabu ash-Shuffah — adalah nama yang diberikan kepada para penghuni satu tempat yang seperti disebutkan di atas yaitu ash-Shuffah. Menurut 


\section{el-'Tarbawj \\ Radiman}

Ibn al-Atsir (t.t.:juz3:37), "Ahl Ash-Shuffah, mereka adalah para faqir dari kalangan almuhajirin, dan orang-orang yang tidak mempunyai rumah tempat tinggal. Mereka berteduh dan tinggal di tempat yang beratap di masjid al-Madinah". Sebagaimana menurut HAMKA (1961:17), "kaum Shuffah, ialah segolongan sahabat-sahabat Nabi yang menyisihkan dirinya di satu tempat terpencil di samping mesjid Nabi”.

Hitungan pasti tentang jumlah Ahl Ash-Shuffah, tidak ada yang dapat memastikan. Di dalam Al-Hilyah, Abu Nu'aim menyebutkan sekitar 101 sahabat yang dihubungkan dengan Ahl Ash-Shuffah. Abu Nu'aim mengumpulkan nama-nama Ahl Ash-Shuffah yang bersumber dari Abu Sa'id bin al-A'rabi dan Abu 'Abdurrahman as-Sulami dalam al-Hilyah serta menambahkan beberapa nama yang tidak disebut oleh keduanya. Mereka adalah sebagai berikut :

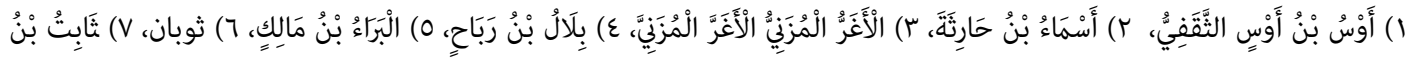

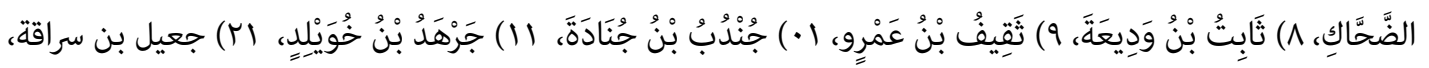

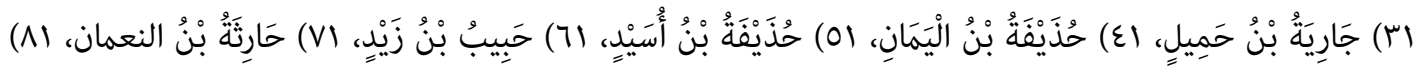

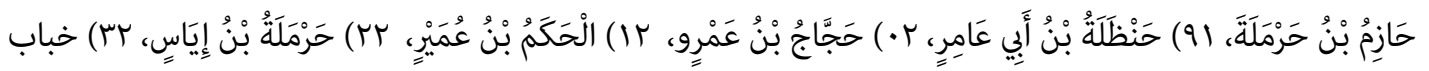

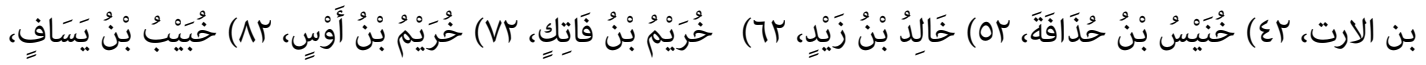

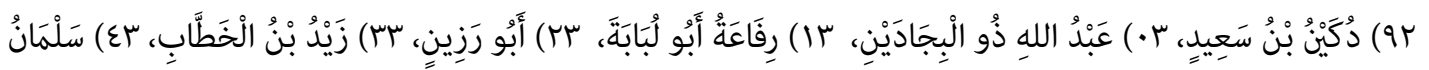

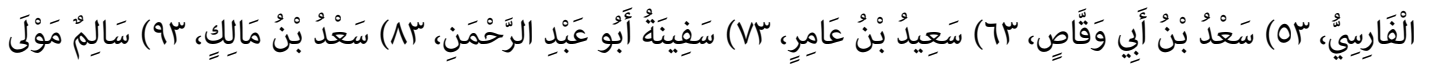

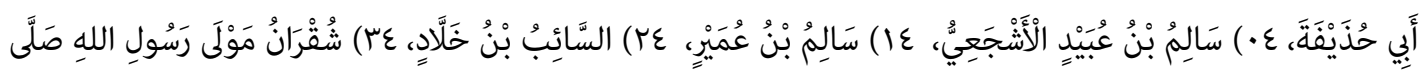

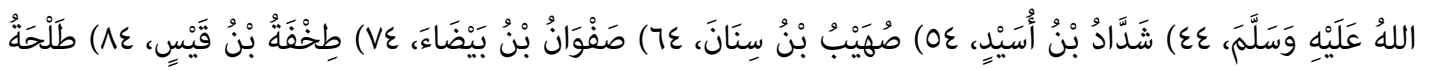

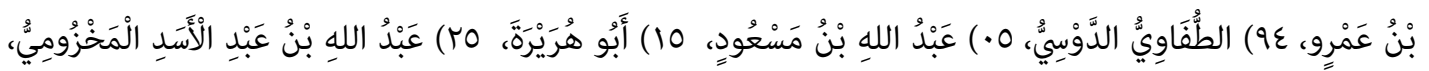

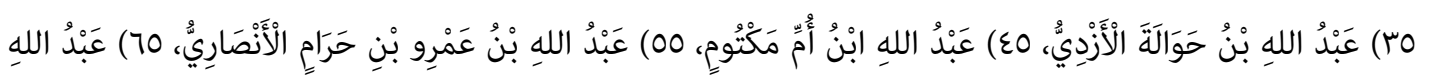

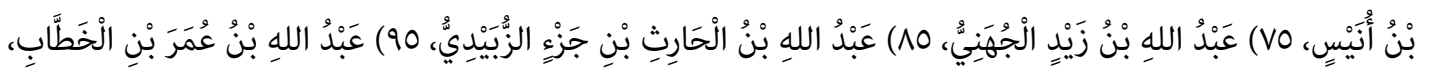




\section{Metode Rasulullah SAW Mendidik ...

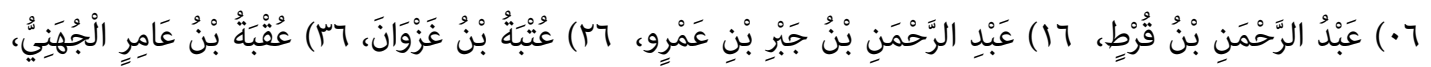

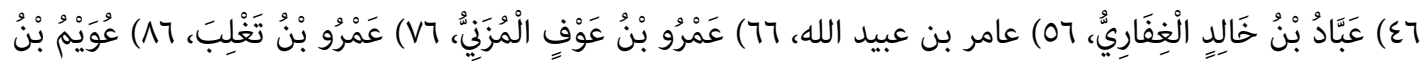

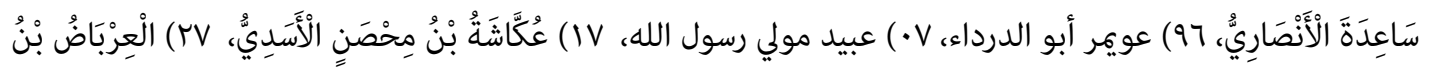

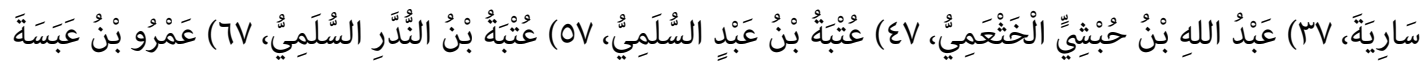

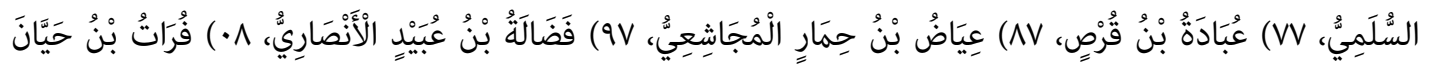

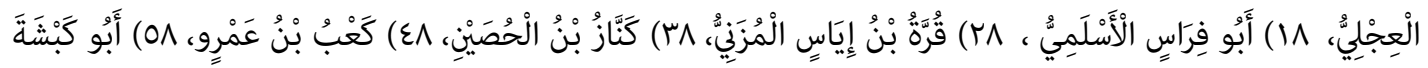

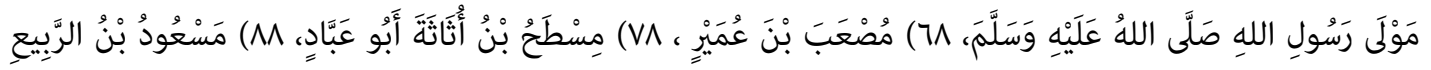

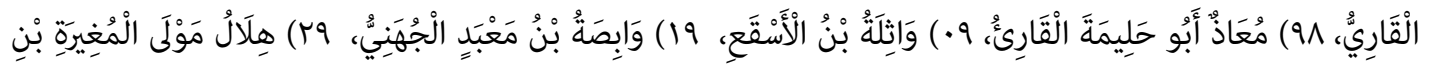

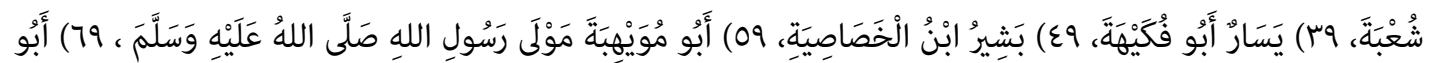

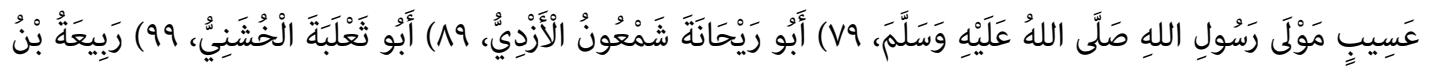

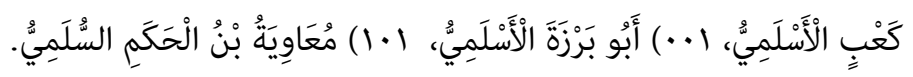

Langgulung (1987:111) berpendapat bahwa konsep Islam dalam pendidikan adalah: 1) menyeluruh , dengan pengertian ia berputar sekitar pengembangan jasmani, akal, emosi, rohani, dan akhlak, 2) utuh, dengan pengertian bukan terbatas di sekolah saja, tetapi meliputi segala yang mempengaruhi pelajar-pelajar di rumah, di jalanan dan lain-lain. Juga ia mengenal pendidikan seumur hidup, 13 abad sebelum pendidikan modern mengenalnya.

Aly (1999:142-144) berpandangan bahwa metode adalah bagian dari peranti lunak (software) dari alat-alat pendidikan. Di mana alat dapat berfungsi sebagai perlengkapan, alat sebagai pembantu mempermudah usaha dan alat sebagai tujuan. Metode pendidikan dapat dibagi menjadi dua macam yaitu metode preventif (langsung atau positif), seperti perintah, nasihat, dorongan, pembiasaan, dan ganjaran; dan metode kuratif (tidak langsung 


\section{Radiman}

atau negatif) seperti larangan, ancaman dan hukuman. Dalam pendidikan keberagamaan manusia maka Tafsir (2014:228-231) berpandangan bahwa harus ada upaya mempercepat terwujudnya manusia sebagai manusia beragama bukan semata manusia yang mengetahui agama. Yaitu melalui metode internalisasi. Proses internalisasi dilakukan melalui pertama, proses peneladanan; kedua, proses pembiasaan.

Tafsir(2013:202) berpandangan bahwa pendidikan pada ranah afektif adalah sangat rumit. Karena menyangkut pembinaan rasa iman, rasa beragama pada umumnya. Dia mengutip metode-metode pendidikan untuk menanamkan rasa iman yang dikemukakan oleh an-Nahlawi yaitu metode hiwar (percakapan) Qur`ani dan Nabawi, metode kisah Qur`ani dan Nabawi, metode amsal (perumpamaan) Qur'ani dan Nabawi, metode keteladanan, metode pembiasaan, metode 'Ibrah dan mau'izah, metode targhib dan tarhib. Untuk selanjutnya dia menambahkan metode pepujian, dan metode wirid. Quthb (1993:324-374) berpendapat bahwa pendidikan dalam bahasan keislaman dapat dilakukan dengan beberapa teknik yaitu pendidikan melalui teladan, pendidikan melalui nasihat, pendidikan melalui hukuman, pendidikan melalui cerita, pendidikan melalui kebiasaan, menyalurkan kekuatan, mengisi kekosongan, pendidikan melalui peristiwa.

Jalal (1988:177-188) menyebutkan beberapa metode mengajar sebagai hasil dari kajian Al-Qur'an dan Hadis, yaitu; 1) partisipasi Guru di dalam Situasi Belajar Mengajar, 2) pengulangan yang bervariasi, 3) membuat perumpamaan dan bercerita untuk mengambil pelajaran, 4) pengalaman pribadi atau widyawisata untuk mencari hakikat dan membaca alam, 5) mengambil pelajaran dari peristiwa-peristiwa yang terjadi, 6) menciptakan suasana senang dalam upaya pendidikan, 7) teladan yang baik, 8) memperhatikan karakteristik situasi belajar mengajar

Dari sekian banyak metode, Tafsir(2013:226) berpandangan bahwa inti dalam metode pendidikan agama menurut Islam adalah adanya rasa hormat dari pihak murid kepada 


\section{Metode Rasulullah SAW Mendidik ...

agama, artinya hormat kepada Tuhan. Ini akan diikuti dengan hormat kepada guru. Guru adalah "wakil" Rasul dalam menyampaikan ajaran suci, Rasul adalah "wakil" Tuhan untuk mengajarkan kesucian itu. Anak-anak sebenarnya menghadapi Tuhan dan Rasul sementara ia berhadapan dengan guru agamanya. Bila kondisi ini ada, maka masalah metode bukan lagi masalah yang penting.

Dalam konteks penyebaran hadis dan keunggulan sahabat dalam penguasaan hadis maka Azami (1977:9) berpandangan bahwa berdasarkan hadis yang ada, maka cinta adalah faktor yang sangat penting untuk proses penerimaan, pemahaman dan pengamalan hadis. Menurut KH. Imam Zarkasy, "Metode lebih penting dibanding materi; tetapi pribadi guru lebih penting dibanding metode.” (Aly, 1990:207)

Peneliti dan praktisi pendidikan Islami telah melakukan formulasi terhadap metodemetode pendidikan bercorak Islam. Konsep-konsep yang terkumpul, menjadi sangat penting untuk dilaksanakan agar praktek pendidikan bercorak Islam dapat terlaksana dengan baik.

Anggapan tentang kemunduran pendidikan Islam saat ini, bersumber pada keengganan untuk menggali dan merealisasikan pola-pola otentik dari pendidikan Rasulullah SAW. Nilai-nilai positif dalam pendidik Islam terkesan terlambat untuk distandardisasikan dalam formulasi Islam. Sehingga perlu usaha terus menerus untuk meramu kembali formula pendidikan Islami yang terpecah oleh sekularisasi ilmu pengetahuan.

\section{Metode Penelitian}

Penelitian dengan judul "Metode Rasulullah SAW Mendidik Ahl Ash-Shuffah", menggunakan format desain penelitian deskriptif kualitatif yang bertujuan untuk menggambarkan, meringkaskan berbagai kondisi, berbagai situasi, atau berbagai fenomena realitas sosial yang ada di masyarakat yang menjadi objek penelitian, dan berupaya menarik realitas itu ke permukaan sebagai satu ciri, karakter, sifat, model, tanda, atau gambaran 


\section{Radiman}

tentang kondisi, situasi, ataupun fenomena tertentu (Bungin, 2007:68)

Data pada penelitian dengan judul Metode Mendidik Ahl Ash-adalah data literer, yaitu data yang diperoleh dari sumber-sumber tertulis yaitu Kitab Hilyat al-Auliya wa Thabaqat Al-Ashfiya, Shahih Al-Bukhari, dan buku-buku lainnya. Berdasarkan derajat sumbernya maka data dibagi menjadi: 1) data primer, yakni data yang diperoleh dari sumber asli yang memuat informasi atau data tersebut adalah Kitab Hilyat al-Auliya wa Thabaqat al-Ashfiya, Shahih Al-Bukhari, 2) data sekunder, yakni data yang diperoleh dari sumber yang bukan asli memuat informasi atau data tersebut yaitu dalam buku-buku lainnya.

Peneliti memilih metode dokumenter sebagai teknik pengumpulan data dengan mempertimbangkan pendapat Bungin (2007: 121-122) yang berpandangan bahwa metode dokumenter adalah metode yang digunakan untuk menelusuri data historis. Sifat utama dari data ini tidak terbatas pada ruang dan waktu sehingga memberi peluang kepada peneliti untuk mengetahui hal-hal yang pernah terjadi di waktu silam.

Berdasarkan pada kebutuhan data penelitian maka tahap-tahap yang dilakukan dan instrumen yang dibutuhkan adalah: 1) Eksplorasi terhadap nama-nama Ahl Ash-Shuffah dengan Kitab al-Hilyah dan software al-Mausu'ah Ruwah al-Hadits. Proses ini bertujuan untuk mendapatkan petunjuk yang yang memadai tentang nama-nama Ahl Ash-Shuffah . Sehingga mempermudah pada proses selanjutnya. 2) Pengumpulan data dengan menggunakan

software Kitab Sembilan Imam Hadis yang diterbitkan oleh Lidwa Pusaka tahun 2009, Gawami' Al-Kalim versi 4.5 yang diterbitkan oleh Islamweb dan Al-Idarah al- Âmmah lial-Auqaf. Sehingga didapatkan data tentang hadits tentang Ash-Shuffah, dan hadis yang diriwayatkan melalui Ahl Ash-Shuffah .

Data dari objek penelitian yang terkumpul merupakan hasil dari pencarian dengan metode digital. Validasi dilakukan dengan mencari pada kitab-kitab versi cetak ataupun versi ebook (format pdf, format djvu dan lain-lain ). Pemeriksaan keabsahan teks dengan 


\section{Metode Rasulullah SAW Mendidik ...

melakukan pencocokan hasil pencarian digital versus Shahih Bukhari dalam format pdf yang diterbitkan Dar Thauq An-Najah, Beirut.

Analisis terhadap data yang diperoleh pada penelitian berjudul "Metode Rasulullah SAW. Mendidik Ahl Ash-Shuffah" menggunakan strategi Analisis Isi (Content Analysis) sebagai salah satu metode dalam metode Analisis teks dan bahasa. Alasan pemilihan metode Analisis Isi ( Content Analysis ) adalah merujuk pada penjelasan Bungin(2007:153) yang berpandangan bahwa tujuan analisis teks dan bahasa adalah untuk mengungkapkan proses etik dan emik terhadap suatu peristiwa sosiologis yang memiliki proses dan makna teks dan bahasa, sehingga dapat diungkapkan proses-proses etik dan emik yang terkandung di dalam teks dan bahasa itu, baik dalam konteks objek, subjek maupun wacana yang berlangsung di dalam proses tersebut. Analisis isi (Content Analysis) adalah teknik penelitian untuk membuat inferensi-inferensi yang dapat ditiru (replicable), dan shahih data dengan memperhatikan konteksnya.

Analisis tekstual terhadap terjemah teks hadis Ahl Ash-Shuffah dilakukan melalui software QDA Miner versi 5.0.2 Langkah yang dilakukan adalah: 1) membuat Category yaitu metode. 2) memasukkan data hadits tentang Ahl Ash-Shuffah dalam software QDA Miner untuk selanjutnya dilakukan coding. Kode-kode yang dibuat adalah berdasarkan pada penjelas teori tentang metode pendidikan. Coding dilakukan terhadap satuan kata, maupun satuan makna, 3) Hasil proses coding selanjutnya dimunculkan dalam bentuk tabel agar mempermudah dalam pengolahan data. Baik data kuantitatif maupun kualitatif , 4) verifikasi terhadap hasil coding yang telah dilakukan. Verifikasi dilakukan untuk melihat sejauh mana satuan makna berhubungan dengan kategori yang sudah ditentukan. Kode-kode baru yang muncul selama proses coding disederhanakan dalam klasifikasi yang sudah ada atau penambahan sub kategori, 5) satuan makna dan kategori dianalisis dan dicari hubungan satu dengan lainnya untuk menemukan simpulan sesuai tujuan penelitian. 


\section{Radiman}

\section{Hasil Penelitian}

Eksplorasi hadis Ahl Ash-Shuffah dilakukan dengan menggunakan kata kunci namanama Ahl Ash-Shuffah pada format pencarian dalam Software Kitab Sembilan Imam Hadits dan memilih Shohih Bukhari sebagai tempat mencari. Hasil dari pencarian tersebut adalah:

Tabel 1. Hasil Pencarian Hadits tentang Ahl Ash-Shuffah

\begin{tabular}{|c|c|c|c|c|}
\hline No Urut & Nomor Rawi & Nama Rawi & $\begin{array}{l}\text { Jumlah } \\
\text { Hadist }\end{array}$ & Persentase \\
\hline 1 & 51 & أَبَوُ هُرَيْرَةَ & 1061 & $58.52 \%$ \\
\hline 2 & 59 & عَبْدُ اللهِ بْنُ عُمَرَ بْنِ الْخَطَّابِ & 245 & $13.51 \%$ \\
\hline 3 & 4 & بَلَلْ بْنُ رَبَاحِ & 81 & $4.47 \%$ \\
\hline 4 & 55 & عَبْدُ اللهِ بْنُ عَمْرو بْنْ حَرَام الَالَنَصَارِيُّ & 74 & $4.08 \%$ \\
\hline 5 & 14 & حُذَيْفَةُ بْنُ الْيَمَانِ & 60 & $3.31 \%$ \\
\hline 6 & 50 & عَبْدُ اللهِ بْنُ مَسْعُوِ & 34 & $1.88 \%$ \\
\hline 7 & 10 & جُنْدُبُ بْنُ جُنَادَة & 26 & $1.43 \%$ \\
\hline 8 & 23 & خباب بن الارت & 26 & $1.43 \%$ \\
\hline 9 & 57 & عَبْدُ الله بْنْ زَيْدِ الْجُهَنِيُّ & 18 & $0.99 \%$ \\
\hline 10 & 35 & سَعْدُ بْنُ أَبَي وَقَاَّص & 17 & $0.94 \%$ \\
\hline 11 & 5 & الْبَرَاءُ بْنُ مَالكِك & 16 & $0.88 \%$ \\
\hline 12 & 38 & سَعْدُ بْنُ مَالِكِكِ & 16 & $0.88 \%$ \\
\hline 13 & 63 & عُقْبَةُ بْنُ عَامِر الْجْهَنَنيُّ & 16 & $0.88 \%$ \\
\hline 14 & 54 & 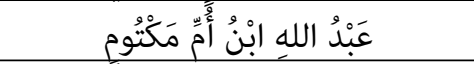 & 15 & $0.83 \%$ \\
\hline 15 & 65 & عامر بن عبيد الله & 13 & $0.72 \%$ \\
\hline 16 & 58 & 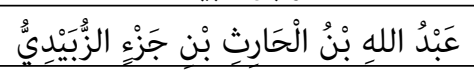 & 12 & $0.66 \%$ \\
\hline 17 & 86 & مُصْعَبَ بْنَ عُمَيْرِ & 12 & $0.66 \%$ \\
\hline 18 & 34 & سَلْنَانُ الْفَارِسِيُّ & 9 & $0.50 \%$ \\
\hline 19 & 66 & عَمْرُو بْنُ عَوْفِ الْمُزَنِيُ & 9 & $0.50 \%$ \\
\hline 20 & 100 & أَبْوُ بَرْزَةَ الْأَسَْلَمِيُّ & 8 & $0.50 \%$ \\
\hline No Urut & Nomor Rawi & Nama Rawi & $\begin{array}{l}\text { Jumlah } \\
\text { Hadist }\end{array}$ & Persentase \\
\hline 21 & 25 & خَالِدُ بْنُ زَيْدِ & 7 & $0.39 \%$ \\
\hline 22 & 7 & تًَابتُ بْنُ الضَّحَّاك & 6 & $0.33 \%$ \\
\hline
\end{tabular}


Metode Rasulullah SAW Mendidik ...

\begin{tabular}{|c|c|c|c|c|}
\hline 23 & 67 & عَمْرُو بْنُ تَغْلَبَ & 5 & $0.28 \%$ \\
\hline 24 & 71 & عُكَََََّةُ بْنُ مِحْصَنْ الَْأَسَدِيُّ & 5 & $0.28 \%$ \\
\hline 25 & 31 & رَفَاعَةُ أَبْوُ لُبَابَةَّة & 4 & $0.22 \%$ \\
\hline 26 & 98 & أَبْوُ تَعْلَبَةَة الْخُشَنَنيُّ & 4 & $0.22 \%$ \\
\hline 27 & 24 & خُنَيْسُ بْنُ حُذَافَةَ & 3 & $0.17 \%$ \\
\hline 28 & 39 & سَالِمُ مَوْلَى أَبِي حُذَنْفَةَ & 3 & $0.17 \%$ \\
\hline 29 & 87 & مِسُطَحُ بْنُ أُثَاثَةَ أَبَوُ عَبَّادِ & 2 & $0.11 \%$ \\
\hline 30 & 99 & 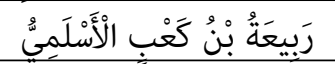 & 2 & $0.11 \%$ \\
\hline 31 & 33 & زَيْدُ بْنُ الْخَطَّاب & 1 & $0.06 \%$ \\
\hline 32 & 68 & عُوَيْمُ بْنُ سَاعِدَةَ الْالَنَمَارِيُّ & 1 & $0.06 \%$ \\
\hline 33 & 90 & وَاثِثلَةُ بْنُ الْأَسَفَعَع & 1 & $0.06 \%$ \\
\hline Jumlah & & & 1812 & $100.00 \%$ \\
\hline
\end{tabular}

Sumber: Software Hadits Sembilan dan Gawami’ al-Kalim ver 4.5

Berdasarkan pada tabel di atas didapatkan petunjuk bahwa: 1) terdapat 1812 hadits tentang Ahl Ash-Shuffah , 2) dari sejumlah 101 Ahl Ash-Shuffah , 33 orang diantaranya tercatat dalam Shahih Bukhari, 3) sahabat Abu Hurairah disebutkan dalam sekitar 1061 hadits atau 58,52 \% dari keseluruhan hadis tentang Ahl Ash-Shuffah . 4) Dengan menjalankan Coding Frequency pada menu Analyze pada QDA Miner diperoleh frekuensi data metode Pendidikan adalah 1913 data.

\section{Pembahasan}

Analisis isi terhadap data tersebut menghasilkan deskripsi tentang Metode Rasulullah SAW. Mendidik Ahl Ash-Shuffah yaitu:

Tabel 4.7. Coding Frequency untuk Kategori Metode

\begin{tabular}{|l|l|l|l|}
\hline Category & Code & Count & $\%$ Codes \\
\hline Metode & Memberi Nasihat & 482 & $25.20 \%$ \\
\hline Metode & Motivasi / ÇáÊN̂́̂́ì & 289 & $15.11 \%$ \\
\hline Metode & Intimidasi/ ÇáÊẼåí̀ & 172 & $8.99 \%$ \\
\hline Metode & Keteladanan & 134 & $7.00 \%$ \\
\hline Metode & Cerita & 129 & $6.74 \%$ \\
\hline
\end{tabular}


Radiman

\begin{tabular}{|l|l|l|l|}
\hline Metode & Demonstrasi/ Mencontohkan & 111 & $5.80 \%$ \\
\hline Metode & Ceramah & 109 & $5.70 \%$ \\
\hline Metode & Perintah atau larangan & 96 & $5.02 \%$ \\
\hline Category & Code & Count & $\%$ Codes \\
\hline Metode & Tanya Jawab & 95 & $4.97 \%$ \\
\hline Metode & Mengambil Pelajaran & 77 & $4.03 \%$ \\
\hline Metode & perumpamaan & 59 & $3.08 \%$ \\
\hline Metode & Diskusi & 51 & $2.67 \%$ \\
\hline Metode & Metode Persuasi & 41 & $2.14 \%$ \\
\hline Metode & Pengadilan & 32 & $1.67 \%$ \\
\hline Metode & Debat & 18 & $0.94 \%$ \\
\hline Metode & Keberkahan & 7 & $0.37 \%$ \\
\hline Metode & Menghafal & 6 & $0.31 \%$ \\
\hline Metode & Mulazamah & 3 & $0.16 \%$ \\
\hline Metode & Permainan & 1 & $0.05 \%$ \\
\hline Jumlah & & 1913 & $100.00 \%$ \\
\hline
\end{tabular}

Sumber: Data Primer diolah dengan QDA Miner

Deri tabel tersebut diketahui bahwa :

1. 482 data atau $25 \%$ menyebutkan bahwa pendidikan terhadap Ahl Ash-Shuffah menggunakan metode memberi nasihat. Diantara hadits yang menggunakan metode ini adalah H.R. Bukhari nomor Hadis 6490 versi software dan versi cetak nomor 6009 .

2. 289 data atau 15.11 \% diketahui menggunakan metode motivasi / التزغيب. Diantara hadits yang diketahui menggunakan metode motovasi adalah sebagai berikut:.”(H.R. Bukhari nomor Hadis 657 versi software dan versi cetak nomor 617.

3. 172 data atau sekitar $8.99 \%$ menggunakan metode Intimidasi/ الترهيب. Diantara hadits yang mengandung metode ini adalah H.R. Bukhari nomor Hadis 5789 versi software dan versi cetak nomor 5343 .

4. 134 data atau sekitar $7.00 \%$ menunjukkan penggunaan metode keteladanan. Diantara hadits yang menggunakan metode keteladanan adalah H.R. Bukhari nomor Hadis 5867 


\section{Metode Rasulullah SAW Mendidik ...

versi software dan versi cetak nomor 5418 .

5. 129 data atau $6.74 \%$ dari keseluruhan data menggunakan metode cerita. Diantara haditsnya adalah H.R. Bukhari nomor Hadis 2269 versi software dan versi cetak nomor 2108.

6. Sejumlah 111 data atau sekitar $5.80 \%$ menunjukkan metode demonstrasi/ mencontohkan. Diantara hadits yang menunjukkan metode ini adalah H.R. Bukhari nomor Hadis 1752 versi software dan versi cetak nomor 1634.

7. Sejumlah 109 data atau $5.70 \%$ menunjukkan penggunaan metode ceramah. Diantara hadits yang menunjukkan penggunaan metode ceramah adalah H.R. Bukhari nomor Hadis 2749 versi software dan versi cetak nomor 2544 .

8. Sebanyak 96 data atau $5.02 \%$ menunjukkan penggunaan metode perintah atau larangan. Hadits yang berkaittan dengan metode ini diantaranya adalah H.R. Bukhari nomor Hadis 2140 versi software dan versi cetak nomor 1996.

9. Sebanyak 95 data atau $4.97 \%$ menyebutkan penggunaan metode tanya jawab. Hadits yang menunjukkannya adalah H.R. Bukhari nomor Hadis 2782 versi software dan versi cetak nomor 2574 .

10. Sebanyak 77 data atau $4.03 \%$ menggunakan metode mengambil pelajaran. Diantara hadits yang menunjukkan penggunaan metode ini adalah H.R. Bukhari nomor Hadis 3663 versi software dan versi cetak nomor 3390.

11. Sebanyak 59 data atau $3.08 \%$ menggunakan perumpamaan. Diantara hadits yang menggambarkan metode ini adalah H.R. Bukhari nomor Hadis 5298 versi software dan versi cetak nomor 4887.

12. 51 data atau sekitar $2.67 \%$ menunjukkan penggunaan metode diskusi. Diantara haditsn- 
ya adalah H.R. Bukhari nomor Hadis 6573 versi software dan versi cetak nomor 6088].

13. 41 data atau sekitar $2.14 \%$ menunjukkan penggunaan metode persuasi. Diantara hadits yang menunjukkkan metode ini adalah:.’(H.R. Bukhari nomor Hadis 7411 versi software dan versi cetak nomor 6862.

14. 32 data atau sekitar $1.67 \%$ menunjukkan metode pengadilan. Diantara hadits yang menunjukkan metode ini adalah: (H.R. Bukhari nomor Hadis 6839 versi software dan versi cetak nomor 6334 .

15. 18 data atau $0.94 \%$ menggunakan metode debat. Hadits yang menunjukkan penggunaan metode ini adalah H.R. Bukhari nomor Hadis 2827 versi software dan versi cetak nomor 2615.

16. 7 data menunjukkan penggunaan mtode keberkahan. Diantara haditsnya adalah: H.R. Bukhari nomor Hadis 5859 versi software dan versi cetak nomor 5411

17. Sebanyak 6 data menunjukkan penggunaan metode menghafal. Hadits yang menunjukkan penggunaan metode ini adalah H.R. Bukhari nomor Hadis 6410 versi software dan versi cetak nomor 5931.

18. 3 data menyebutkan istilah mulazamah sebagai metode pendidikan. Haditsnya adalah H.R. Bukhari nomor Hadis 3708 versi software dan versi cetak nomor 3432.

19. 1 data tentang penggunaan metode permainan adalah H.R. Bukhari nomor Hadis 2674 versi software dan versi cetak nomor 2478.

Berdasarkan kategori dan teori yang diinduksikan kepada metode Rasulullah SAW. mendidik Ahl Ash-Shuffah, maka didapatkan relevansi pendidikan Ahl Ash-Shuffah dengan pendidikan Islam saat ini, metode pembelajaran yang ditemukan pada Metode Rasulullah SAW. Mendidik Ahl Ash-Shuffah adalah ceramah, cerita, 


\section{Metode Rasulullah SAW Mendidik ...

debat, demonstrasi/mencontohkan, diskusi, hukuman/الترهيب, keberkahan, keteladanan, memberi nasihat, mengambil pelajaran, menghafal, persuasi/الاقناع والاقتناع , motivasi /التزغيب, mulazamah, pembiasaan, pengadilan, perintah atau larangan, permainan, perumpamaan, tanya jawab. Metode-metode tersebut sebagian besar masih relevan dan dipergunakan dalam pendidikan. Metode yang dianggap tertinggal dengan teori pada saat ini adalah menghafal, keberkahan dan mulazamah. Meskipun dianggap tertinggal, namun metode ini masih menjadi andalan dalam beberapa cabang ilmu.

\section{Kesimpulan}

Dari hasil pembahasan di atas maka dapat diambil kesimpulan bahwa metode Rasulullah SAW mendidik Ahl Ash-Shuffah meliputi beberapa metode, yaitu metode memberi nasihat, metode motivasi / التزغيب, metode Intimidasi/ metode keteladanan, metode diskusi, metode persuasi, metode pengadilan, metode keberkahan, metode menghafal, mulazamah, dan metode permainan. Sedangkan metode-metode tersebut menunjukkan relevansi yang sangat erat kaitannya dengan perkembangan pendidikan umum dan pendidikan Islam khususnya pada masa sekarang.

Penelitian dengan judul Metode Rasulullah SAW mendidik Ahl Ash-Shuffah merupakan ikhtiar kecil peneliti untuk mengetahui interaksi Ahl Ash-Shuffah dan Rasulullah SAW. Sehingga mendapatkan deskripsi dari metode Rasulullah SAW ketika mendidik para sahabatnya yaitu Ahl Ash-Shuffah. Namun usaha kecil ini masih jauh dari sempurna dan perlu penelitian lebih lanjut sehingga didapatkan hasil yang jauh lebih komprehensif tentang pendidikan pada masa Rasulullah Muhammad SAW.

Saran kepada para pemegang kebijakan pendidikan, baik instansi negeri maupun swasta, lembaga maupun perseorangan, peneliti berharap agar segera dilakukan perbaikan terhadap 


\section{elvirarbawj $_{\text {Ratiman }}$}

komponen-komponen pendidikan yang ada sehingga diperoleh lulusan yang menempatkan tujuan akhir sebagai orientasi pendidikannya. Dan menghindari pemisahan nilai duniawi dan ukhrawi sehingga didapatkan lulusan yang mempunyai kecakapan jasmani, rohani, dan sosial. 


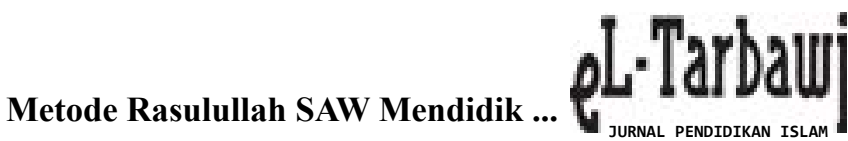

\section{Daftar Pustaka}

---. (1425H/2004H). Al-Mu'jam al Wasith ( Cetakan ke-4).Mesir:Maktabah al-Syuruq al-

Dauliyah

---. (2009). Software Kitab Sembilan Imam Hadits. Indonesia:Lidwa Pusaka

---. (2016). Software QDA Miner versi 5.0.2. --:Provalis Research

---.t.t. Software Gawami’ Kalim Ver 4.5. ---Islamweb

Al-Asfahani. Abi Nu'aim Ahmad bin ‘Abdullah. (1416H/1996M). Hilyat al-Auliya wa Thabaqat al-Ashfiya ( Jilid1-2). Beirut:Dar al-Fikr

al-Bukhari, Abu 'Abdullah Muhammad ibn Isma'il. (1422H). Al-Jâmi ash-Shahih. Beirut: Dar ath-Tahuq an-Najah

al-'Umariy, Ikram Dhiya. (1403 H-1983M). Al-Mujtama' al-Madani fi 'Ahdi An-

Nabawiyah : Khasa isuhu wa tandzimatuhu al-ula. Madinah. Al-Jami’ah al-Islamiyah bi al-Madinah

Aly, Hery Noer.(1999). Ilmu Pendidikan Islam. Jakarta:Logos

At-Turmusy, Muhammad Mahfudz bin ‘Abdillah(1324 H), Manhaj Dzawi an-Nadhar fi Mandzumati 'Ilm al-Atsar. Riyadh:--

Bukhari, Imam, Shahih Bukhari, Semarang, Toha Putra.

Bukhari, Imam. (1400 H). Al-Jami' Ash-Shahih. Kairo: Al-Maktabah As-Salafiyah

Bungin, Burhan.(2007). Penelitian Kualitatif: Komunikasi, Ekonomi, Kebijakan Publik, dan Ilmu Sosial Lainnya. Jakarta:Kencana

Daradjat, Zakiah., versi software dan versi cetak nomor et al.\}. (1996). Ilmu Pendidikan Islam. Jakarta:Bumi Aksara 
HAMKA,--. (1940). Tasauf Modern. Djakarta:Djajamurni

Ibn al-Atsir. Majid ad-Din Abi As-Sa'adat al-Mubarak bin Muhammad al-Jazari. (--). AnNihayah fi Garib al-Hadits wa al-Atsar. Riyadh: Al-Maktabah al-Islamiyah

Itr, Nuruddin. (1979). Manhaj an-Naqd fi 'Ulum al-Hadits. Damsyiq: Daar Al-Fikr

Jalal, Abdul Fattah. (1988). Azas-azas Pendidikan Islam(Penerjemah Herry Noer Ali).

Bandung:cv.Diponegoro

Langgulung, H. (1987). Asas-asas Pendidikan Islam. Jakarta, Indonesia: Pustaka Al-Husna

Nata, Abudin. (2011). Sejarah Pendidikan islam. Jakarta:Kencana

Quthb, Muhammad.(1993). Sistem Pendidikan Islam (terjemahan Drs. Salman Harun).

Bandung:PT. Alma'arif

Rahman, Fatchur. (1991). Ikhtisar Mushthalahul Hadits. Bandung:PT. Alma’arif

Sukmadinata, Nana Syaodih. (2014). Pengembangan Kurikulum:Teori dan Praktek.

Bandung:PT. Remaja Rosdakarya

Tafsir, Ahmad. (2013). Ilmu Pendidikan Islam. Bandung:Penerbit Rosdakarya

Winsick, A. Y. (1936). Al-Mu'jam al-Mufahras li alfadzi al-Hadits an-Nabawi. Leden:

Maktabah Brail 